\title{
Managing uncertainty - principles for improved decision-making
}

[Institute and Faculty of Actuaries (IFoA), Sessional Research Event, London, 18 February 2019].

\begin{abstract}
This abstract refers to the following paper: Aggarwal, G., Bird, C., Cox, A., Durkin, T., Kaye, P., Marcuson, A., Masters, T., Regan, N., Restrepo, S., Shah, N., Smith, A., Stock, R., Strudwick, M., Toller, J., White, W., White, S. and Wilkinson, R. Managing Uncertainty: Principles for Improved Decision Making.
\end{abstract}

The Chair (Dr L. M. Pryor, F.I.A.): I am chair of the Resource and Environment Board and I also sit on Council.

Our speakers are:

Paul Kaye, who has oversight of the actuarial practice at Aon within reinsurance solutions in London and a more recent focus on aviation. He has wide-ranging practical experience from underwriting, reinsurance analysis and strategy to capital modelling, and has worked with a number of large European and global insurance groups. He worked for Commercial Union before joining Benfield Gregg some years ago.

Alex Marcuson is managing director of Marcuson Consulting, a team of 10 general insurance (GI) actuarial and risk specialists. Based in the City of London, they advise insurers, reinsurers, investors and banks, recently helping them to manage uncertainty through Brexit. He is a member of the profession's GI reserve oversight committee and one of the GI specialists on the professional support service, an anonymous facility run by the IFoA to help actuaries with technical and ethical dilemmas. That is a welcome reminder to everyone that if they do have a technical and ethical dilemma, an ideal thing to do is to call on the professional support service.

Joe Lo, who is going to be closing the discussion, is head of actuarial R\&D at Aspen with an interest in capital modelling, pricing, catastrophe modelling and risk management. He has been chair of a number of working parties, Practicing Ruin, for example. He has also participated in the Getting Better Judgement working party. He has been on the General Insurance Reserving Oversight (GIRO) committee and was deputy chair last year. He is now chair of the GI research and thought leadership subcommittee.

Melinda Strudwick is a director working in PricewaterhouseCoopers (PWC). She has over 15 years' experience in the non-life insurance industry. She advises many UK, European and London market insurers and reinsurers, spanning personal and commercial lines and Lloyds and the London market. She leads a range of actuarial risk and regulatory services and specialises in risk and capital management, and she is the co-chair of the Institute and Faculty of Actuaries (IFoA) GI Managing Uncertainty working party.

Martin White's range of career experience, together with a longstanding personal interest in investment, has made him put a lot of personal time into the operation of the investment process more widely. This is a way of using his actuarial knowledge and insights gained from work in the wider public interest. He is a founder member of the UK Shareholders' Association and has recently developed a

\footnotetext{
(c) Institute and Faculty of Actuaries 2019. This is an Open Access article, distributed under the terms of the Creative Commons Attribution licence (http://creativecommons.org/licenses/by/4.0/), which permits unrestricted re-use, distribution, and reproduction in any medium, provided the original work is properly cited.
} 
new initiative which is still in its early stages called Savers Take Control. He also continues to contribute to the IFoA's GI board through volunteering on several subcommittees and working parties.

I would also like to welcome Chris Bird, who is one of the other co-chairs of this working party, along with Melinda (Strudwick) and Martin (White). Andrew Smith, the fifth one, is not able to be here, as he is in Dublin. If you have read the paper, this is a fantastic example of how working parties can just keep going and worry away and worry away until they have reached some really good conclusions, so well done everybody.

So, first I would like to start off with Paul (Kaye), who is going to give an overview of the principles, and then Alex (Marcuson) is going to be looking at a case study.

Mr P. Kaye (opening the discussion): Thank you, Louise (Pryor). I would like to start off by putting a question to you all. When you have a problem, or a decision to make, on which of these options do you tend to focus?

Do you tend to focus on the issues that are more certain? Maybe you consider uncertainty but then put it to one side. Maybe you think, "That is a bit tricky. I will make three or four key assumptions," and maybe list them as caveats. Maybe you attempt to do a more sophisticated quantification of uncertainty. Perhaps you take a much broader approach and consider how uncertainty can be managed in the context of an actual decision.

I think it is this last point that really brought the working party together. It was originally formed, in about 2012, with the 1-in-200 working party, but the following year it morphed into the Managing Uncertainty working party with a much broader aim and goal, which we will talk about in a moment.

Seventeen authors are listed in the paper, but there have been over 25 contributors. So it is been a mammoth effort over the years.

When we looked at uncertainty, we were really faced with this sort of situation. You have the challenge of how well you can define the problem. But, assuming you have managed that, a huge number of the problems are clearly quantifiable: there is proper, quantitative analysis you can do to address them.

We would characterise those as being modelling challenges, which many in the room will know and love and be familiar with.

There are, however, many problems in the world where the amount which we can honestly quantify is quite small, with a lot which is unknowable. An example might be: "What might my cyber underwriting strategy be?"

If I am a motor insurer: "How will my competitors behave or will there be a legal change?"

I am thinking of buying a house, so there are certain things you could model, but what are your future needs? What will you need in 20 years' time? What is your future ability to meet your mortgage payments? "Will I like the neighbours?" They are all problems which are very, very uncertain.

One key point about the working party we wanted to be really clear about was our focus on decision-makers. Our focus was not just on advisors of decision-makers and actuaries, it was far broader than that. By looking at decision-makers, we are also considering the other people involved in the decision, such as actuaries and other expert advisers, and how can they make better decisions?

We are not offering a toolkit or an algorithm. We are offering a set of principles to help a more structured thought process with a simple aim of just making a better decision than you would otherwise make.

A key question, I think, for this community, is what can this community do to be more relevant in those non-quantification scenarios? Given some good, rigorous analytical thought, how can we improve the role you have?

So, we have our own principles. The first principle is the key one, facing up to uncertainty. It raises the question why do people dodge uncertainty? I think the first point is there is a biological reason. Your brains are programmed to be pattern recognition machines. They are looking at evidence, memories and experience, to try and predict what is going to happen next. 
The second point is time. We do not often have much time, we are in a rush and we cannot spend loads of time on uncertainty. If you are an individual faced with making a decision, you can often just get lucky.

There is often not much alignment between thinking about good management of uncertainty and your short-term rewards and your personal risk. Also, if you are in a group where you think there is a big uncertainty issue, and if you are the one to raise it, it is quite likely you will meet resistance. You know, you are raising things which people just do not want to know about. You are going to delay things, and you are going to create extra confusion.

Which really brings us to the third reason why people struggle to face uncertainty: it is what do you do about it? That really brings us onto our suggestion of the next principles.

Deconstructing anything is a generally useful thing (doing lists of things), but in the paper we offer three specific deconstructions we think are of interest. One is to deconstruct the decisionmaking process. So, the original framing of the question is really clearly understood. What sort of analysis or thinking is going to take place to answer and respond to the question? Then, finally, what about the results, the communication, how will it influence the decision.

The next action is to look at the stakeholders. Who has to make the decision, who are the influencers of that decision-maker and who is impacted by the decision? Sometimes you have people who are impacted by the decision who have a key role and can influence, and others are victims of whatever decision is made.

We offer the point about looking at assumptions. So, whenever you look at a particular situation, there are a lot of assumptions about where you are now and where you might be a few years down the line, having made the decision.

Some of those assumptions are very explicit and clear, but a lot of key assumptions are often implicit, and it is quite interesting to identify what are those assumptions which no one is talking about but which are quite key to the decision.

We have seven categories listed in the paper of types of uncertainty. It is quite interesting to take your assumptions and map them and see what types of uncertainty do exist for those assumptions. The matrix can be quite insightful in terms of informing what you are facing and what you are meant to do.

The next principle is: do not be fooled. One key point is, where you have a situation with a lot of uncertainty, biases are really, really powerful.

So, we have two parts. One is where we have intentional bias, for example, when you have a very deliberate agenda and you are really into how do I play the game? Often you have an expert advising the decision-maker, where you have different information between you, different perspectives and different motivations.

So, in an actuarial sense, if someone is doing a reserving exercise for a very difficult class, you might have your opinion of the range of outcomes, but the decision-maker has an absolutely invested view about what the outcome should be. It might affect bonuses, or it might be particular outcomes are expected. I think, professionally, if you encourage everyone to declare their hand and give everyone full information, that might not be the most sensible negotiation strategy.

We then have unintentional biases, where there is a whole plethora of different biases which, again, we can deconstruct into different types. The real point of those is that you can be caught out. Those that have read Daniel Kahneman's book - Thinking Fast, Thinking Slow - are going to be familiar with the idea that one of the best ways of countering unintentional biases is to stimulate slow thinking, that is, ensure the people in the room step back and recognise what might be going on so they can be aware and have their eyes more open to what is happening.

Models can be helpful but also dangerous. There was a psychologist called Gerd Gigerenzer, a German professor, who has a very interesting insight about a spectrum of where you would know things on one side all the way through to complete unknowability. He would argue that, where you know the probabilities, such as when you go to a casino, then you can model with 
absolute confidence, and that is the right thing to do. As you move away from knowability, the robustness of using models becomes challenging and he would argue using more simple heuristics ought to be given a more equal hearing as to their value.

You can still have bad heuristics, but maybe a complex model is no better than a very simple, good heuristic in a really unknowable situation. That is not to say that models do not have a powerful role in areas of high uncertainty, but just that you have to be more aware about how they are being used and how they are influencing the decision.

We then move onto thinking about adaptability and resilience. It is about building in preparedness. If things do not turn out as you have planned, are you ready for that? Do you have options? Have you planned for different potential outcomes, even if you are not sure what might cause them? So, we list a range of ideas for doing that.

The last principle is around bringing people with you. Having a technical view on uncertainty is fine, but unless everyone is with you, it will not have much impact. So, we talk in the paper about resistance. How can you spot resistance? How can you understand it? How can you manage it? How can you build trust? If you are advising a decision-maker, how can you get some trust going? Similarly speaking, the decision-maker, how can they build a rapport with their expert advisor?

So, there is the whole issue of engagement and knowledge, or understanding, of the problem. Does the decision-maker know enough about the technical issues of a complicated thing to be informed enough to take the decision? It is a key issue.

Finally, you have the issue of communication. Understanding what to share and how you should do that. So, these are a set of semi-theoretical principles, but thought through in a very practical way. We are well aware that the real value of these principles comes when we look at how they are applied in real situations. How useful can they be to make better decisions?

Mr T. A. G. Marcuson, F.I.A.: I want to start by making a quick nod of acknowledgement to some of the original contributors, as it were, who dared to ask the questions that ultimately led to this paper. Part of the reason for recognising this is just the time span over which the ideas have evolved and emerged. The first paper that I want to mention is Andrew Smith's paper at GIRO in 2004 entitled: The Best Workshop for 200 Years. This was well before Solvency II was in place, but it did pose the question: does the 99.5 percentile make sense?

Fast-forwarding 7 years, Mark Graham's paper at GIRO in 2011: The Great 99.5 Percentile Swindle, really did set the proverbial cat amongst the pigeons, with Solvency II's introduction imminent. How little we knew back in 2011 that we still had another 5 years awaiting the pleasure of its arrival. Amongst other things, Mark exhorted the profession to issue a statement setting out how actuaries can add value to the Solvency Capital Requirement (SCR) but also making very clear the inherent impossibility of calculating the 99.5 percentile with confidence.

So, out of this came the 1-in-200 working party, which was formed in 2012. As Paul (Kaye) mentioned, very quickly, it became clear that the problem was much wider than simply a 1-in-200 problem, and there was need to find a way to respond, as a profession, in a constructive fashion.

The more we looked into the issues and debated them, the more we found that the ideas applied far, far more widely. For example, what could we learn from what climate scientists were doing and how they were expressing the challenges they were facing in influencing policy? Much closer to home, what about the issues of uncertainty which affect our day-to-day work in all of our domains, whether advising on the reserves to book or considering the right price to pay in an acquisition scenario?

Which brings me, quite neatly, to the case study, which contains many of the real-life problems that the actuary of today must address.

So, you work for a firm that is buying another firm. Question one, how do you go about valuing it? Question two, given the extra information about the price that is being asked for the company, 
how are you going to go about framing your advice? Then question three, your CEO still wants to go ahead, what should you do?

Importantly, you can reframe this question and the responses that I am going to talk about as, "You are a non-executive director sitting on the board of the company and you are in receipt of the actuary's advice and are trying to work out what decision to take." For simplicity, I am going to express myself through the eyes of the actuary providing the advice, but I think you can make the assumptions and interpretation as to how it might apply more widely. Before going on to focus on question three, which is the critical question, let us talk briefly about how we might go about answering question one.

So, if you look at it, and look at the detail of the ideas that we are able to generate, it is really a bit of an exam question. As actuaries, we are trained to be able to bring out a very wide range of valuation factors.

Now, while this level of response would, I hope, score highly in a professional exam, in our experience it falls short when it hits the real world. This zone, between exams and the real world, is where the working party is focused. Clearly, we have a great deal of expertise here, but a question for you to consider is whether it is better for us to bring our expertise and work with others, or to position ourselves as the expert and not claim to have the wider answers and to be involved in that discussion.

In the interest of time, I am going to skip forward to question three. I want to stress that this paper is not suggesting for a moment that we discard the detailed input from question one that we can give. Rather, while this knowledge gets us to the table, it only provides half of the answer, and we have much, much more to offer.

So, our CEO is adamant that the acquisition should proceed, that is, at the price $20 \%$ above what we think is our estimated value of this company. What should you do? Well, you think very hard. Hopefully, now you have read the paper, you will reach for this paper to guide you. Then you feel inspired with some ideas. I am going to pull out a few of the ideas triggered by the principles which appeal to me and the working party members, just to show you how they are intended to work in practice.

So, our first principle, Face Up to Uncertainty, suggests here that we should be thinking about how much of the problem our modelling is addressing. Although instinctively we want to say that we are valuing a company and we have taken into account all the relevant factors, the reality is we are in the realm of there being lots of things we have not modelled and, more importantly, that we cannot even begin to think about how to model.

There are upside factors, downside risks that we need to think about, knowable scenarios like the US asbestos claims of the 1980s and 1990s, the sort of knowable scenarios like cyber perils and then just the unknowable things that nobody has even considered. We have a CEO and the others on the board of the company who are pushing hard to do a deal, and, as the actuary, we feel the pressure mounting up and up.

The potential for us to receive biased information, and even to kid ourselves, grows with the increasing uncertainty in the situation. "Surely it cannot be as bad as ...," or, "If I exclude considering this scenario ..." These can be dangerous things to think in a high-stakes transaction environment.

So, what do you do? How do you engage constructively and professionally in this situation? It is not, and should not be, your job to sign off the price at which the transaction can go ahead. You are wise to resist pressure to do so.

Then again, neither are you free to adopt the unhelpful approach of walking away from the decision once you have provided your advice. Once we have admitted our ignorance in the face of the problem, we can start to work out how we might go about tackling it by, of course, Deconstructing the Problem. What, really, are the things that should be keeping us awake at night or more generally, what is the question that we really need to try and answer? Given this, how best are you going to go about helping the company to answer it? 
Thinking through these questions leads, naturally, to questions of adaptability and resilience. Will the acquisition enable the company to achieve its strategic goals? Maybe the premium price will be well worth it for the competitive advantage.

I might have explored further the "Do Not be Fooled" principle. The CEO is thinking about her own adaptability and resilience and is heavily biasing the decision because she wants to preserve her job rather than letting the firm be gobbled up by a larger rival.

Having an understanding of the context makes a significant difference to how we position our advice. Perhaps everyone can live with the company paying too much, but it is really important to help the directors to understand what might go wrong and how costly this might be. Does the company really have the resources to overpay? Maybe, with this insight, other arrangements can be put in place to make the transaction work more safely. Just as importantly, do we understand what assumptions underpin more favourable outcomes, so that a cold-eyed view can be taken on whether this is a deal that should be done? If so, is the firm ready to take the steps that are necessary to ensure that these outcomes can be achieved?

Finally, at times like this, it is important to recognise that relying on a formal set piece presentation of advice may not be the best way to ensure colleagues understand our point of view and any concerns that we may have. To bring people with us, it is important for us to obtain a handle on their perspectives and to help them to understand our perspective. Tell them, the board that is, tell them early, tell them often, and tune into the language as you tell them, so that they too can Face Up to Uncertainty and apply all of the six principles.

Our six principles provide an ideal framework within which to make decisions, whether you are acting as an advisor or a decision-maker and whether buying a company, buying a house or buying a car, this toolkit will help. From the largest political dilemmas of today to the smallest parochial concerns, they help us to frame a good decision. As such, I hope that this paper has gone a long way to answer the questions raised by the authors that I mentioned at the beginning and I, and my fellow working party members, look forward to the discussion.

The Chair: Thank you, Alex (Marcuson) and Paul (Kaye). We are now going to open up to general discussion. It certainly struck me, reading the paper, how generally applicable it was, and I think I would particularly be interested in hearing comments on how people have addressed non-core uncertainty. The sort of uncertainty that we do not think about enough, possibly, in our working lives as actuaries. So, how applicable might the framework be outside insurance, for example, to broader social uncertainty such as climate change? Personally, I would be really interested in hearing about that, and I know the presenters would too.

Mr C. M. Smerald, F.I.A.: I am a GI actuary. I have been leading some research that is related to this topic, looking at better sensing and responding to change and on the communication of complexity. One of the things we talked about is the fact that uncertainty is a critical issue to us.

Imagine there is a wooden box I am painting, maybe, the bottom of it for one working party and maybe another side. You are addressing, maybe, the top and another side. So, one of the gaps, and not a gap in that you have done something wrong, but a gap in the sense of something not yet addressed, is the whole tactical side.

I could find a single sentence where you talk about modelling, and there is a huge amount of depth there if only we open that box a little wider. So, for one, I think this is great and I think, as a profession, we should probably meet and talk about the whole box and get Pandora out and really get going.

One thing that struck me is the link between uncertainty and complexity and you use complexity a lot, I think maybe 69 times or something like that, and uncertainty hundreds of times. So, I do have a question, perhaps, about what you see as the link between complexity and uncertainty. 
I do a lot of work with complexity, and certainly there are things in model complexity, as I said, that are not being addressed, in terms of human strategies. My sense is that this paper is around people strategies for dealing with uncertainty.

One of the key tenets of complexity theory is that diversity is a really powerful tool in addressing uncertainty. I see hints of it in your paper, and in your examples, but I do not see the word diversity used at all in the paper, having done a word search. So, I am curious whether that is something the authors would consider talking more about.

The Chair: I think we will try and take a few questions, and then return to the panel. Would anyone else like to follow up on that? It strikes me that not only is there a huge link between complexity and uncertainty, but often uncertainty is caused by the sheer complexity, because it means that things are just too complex to navigate around. Does anyone have any good examples of where that is happened to them?

Mr D. Simmonds: I think one of the things I want to think about is why we are worried about the uncertainty in the first place. Exactly what is the problem?

So, it might be very uncertain as to who is going to win the 3:15 pm at Chepstow, but you are only going to be worried about it if you are going to put on a bet. If we are thinking about uncertainty of climate change, then I think we need to dig down as to which bit of uncertainty is worrying? What is worrying the decision-makers that we are advising? If we are the decisionmaker, then what is worrying us? So, in the case of climate change, are we really worried about sea levels rising? Is it lack of food in drought?

I think we need to get to the bottom of why has this problem arisen? In the case of Alex (Marcuson)'s example, perhaps the first question is, why is the CEO thinking about buying this company? That might narrow down how you address the problem.

The Chair: I think that is a very good point because, after all, we are all meant to be thinking about how what we say is useful to the people who are making the decisions based on our advice. Sometimes one of the problems is that you are assuming that you know what is going to happen, whereas in fact you do not. So, there is almost unexpected uncertainty coming up there.

Mr C. D. O'Brien, F.I.A.: I agree with what the authors are saying, that the models can be helpful but they may be dangerous. It reminds me of 2009 when there was a big flood in the Cumbrian town of Cockermouth. The environment secretary, a well-known modelling expert, of course, said that the flood defences were geared to floods of one in every 100 years, but this was probably nearer one in a thousand.

I would hope better modelling experts were at Aviva, who in the same year said, "It can be argued that the economy has experienced six 1-in-200 year events in the past century." So, yes, models can be helpful and, indeed, they may well be essential, but we do need to learn from where they have gone wrong in the past and be prepared. There may be some more quotations in the future similar to those two that I have provided.

My other comment is about objectives, because if we are talking about making decisions then we need to think about what is the objective of the exercise? If we have in mind a proprietary insurance company, then we probably have in mind something like maximising shareholder value. So, you would expect that decisions would be taken with that in mind.

So, if you ask me, "What would be the risk appetite of the firm?" I would say, "We have an appetite for any risks that will increase shareholder value." It is that straightforward. My pricing strategy, my staff renumeration strategy, will be geared to maximising shareholder value. Clearly, the risk management strategy has to be as well. So, if the regulator comes to me and says, "I think you should have a prudent risk appetite," and I think about that and maybe I decide that, well, we 
should have rather fewer risks than I might otherwise have been taking. If that does not produce the highest level of shareholder value, then it is not really a sustainable strategy because there will be another set of directors who will take the optimal set of risks and the firm will be taken over. This happens in case study B of the paper.

It is not just maximising shareholder value that is of interest, and another thing that was hinted at in the case study that has been provided was that the decisions are taken by directors, or executives, and they may have different incentives and, hence, objectives.

There is a wide body of research that shows that firms where the directors have large numbers of share options take more risks. Now, I would not like to say what the optimal level of share options is, but it is really something that does need to be considered. It may well be that there are some chief risk officers here. They think about risk and shareholder value and probably find that analysing the link between risk-taking and shareholder value is quite difficult, but they also need to think about the contracts of the directors and their renumeration structures. They will also be important.

Mr M. G. White, F.I.A.: It is very interesting to hear that brought up. Shareholder value is an amazingly powerful idea. It is something like 30 years ago where the idea was suggested that what managers should do was a combination of maximising dividends and share price in the near term. If you incentivise people to focus on share price in the near term, for example, by giving them share options, it is also very arguable that they will not think about the long-term creation of wealth and the company's long-term competitive strategy. So, arguably, you can end up destroying shareholder value by being too focused on creating it.

Mr O. Achara, F.I.A.: I would be interested in hearing from the panel about the natural desire to quantify the unquantifiable. I think that is an issue for actuaries, even when we say we do not know something, that people still will ask us, "Well, how much uncertainty is there? Can you put an amount on how much uncertainty is there?" It would be interesting to understand the view of the panel as to how to communicate uncertainty effectively.

Mr Kaye: If you take my example of identifying all the different assumptions, both explicit and implicit, through that you will also stimulating thinking slow. You can encourage your audience to engage with what really are we assuming here and do we honestly understand everything?

It is not about how much uncertainty? That implies some sort of quantification. I think it is just saying there is something here that matters, and it is potentially important.

Maybe going back to the point about making decisions, I think you have to look at each decision. Sometimes, for some decisions, there is all sorts of uncertainty which is not relevant to the decision. So, by deconstructing it, hopefully, you can identify which bits matter.

Picking up the point about complexity, and deconstructing to work out which bits of this horribly complex issue we need to focus on and engage people, I think is a really important thing. I believe it is a thought process in a particular situation which, hopefully, leads to better decisions rather than it being an algorithm which comes up with the answer.

Mr T. J. Birse, F.I.A.: I have seen on not a few occasions in my business career management opting out of making difficult decisions by effectively showing a desire to quantify the unquantifiable. In other words asking the advisors for more information which they probably cannot give, or is too detailed and it is masking a poor management trait of not grasping the nettle.

The Chair: So, is it that they are not facing up to the uncertainty? 
Mr Birse: Absolutely, and not realising that is what is happening. They are just assuming that, "If there is some uncertainty there will be some clever people who will be able to deconstruct it enough and do some sums and, then I will have some numbers. Then I will be able to make a decision."

You are never in that space in the real world. You have to make decisions at times.

Miss M. J. Strudwick, F.I.A.: That was an example that we certainly talked about as a group, in the context of the financial crisis where you had credit default instruments that were very complex which created a lot of uncertainty because you do not know the underlying risks.

The experts were being asked to value these instruments, and that was impossible at that point to do because the market benchmarks on the risks had been shown to be wrong because prices were falling. So, at that point, having the confidence to say, "This is a situation where there is too much uncertainty and we cannot respond. We cannot produce an estimate that you can then lean on in your future decision-making," is a really important route for people to be able to go down.

It helps the user of your work to understand how uncertain the situation is, and the need to open up to some of the other ideas that we put forward in the paper, such as resilience and using resilience as a toolkit instead of a modelling toolkit to solve a problem. So, I completely agree.

Mr White: That same comment made me think about the early days, when I studied the directive coming out in Solvency II. It took many hours, but what struck me was the presumption by the people who designed it that the solution to uncertainty was just to require more and more technical work. If you look, I think you will see that presumption and I think, partly because of that, we ended up with our 1-in-200 for 1 year only objective.

Mr G. Kakar, F.I.A.: The paper is quite interesting. The principles laid down could be applied to any scenario: not necessarily just to the decisions we take, it could also be applied to any decision.

The recent example that comes to mind is Brexit uncertainty. These policies and principles can apply to that scenario as well, about the stakeholders, the government and different departments. It would be useful to generalise these principles so that they can be applied in any decision-making scenario. It might provide some food for thought for a public affairs committee.

My second comment is on the importance of bringing people with you. I am assuming this means bringing people with similar kinds of views, or it could be bringing people with a completely different point of view so that you are challenged. In that process, you tend to either increase uncertainty in the short term or in the long term you reduce uncertainty or the risk of taking wrong decisions.

How do you define uncertainty? Is it the risk of taking wrong decisions or is it a variance around the mean, which is the more technical definition to which we are more accustomed?

Overall, I am very pleased to see this paper and the principles laid down there.

Mr R. A. Galbraith, F.I.A.: I work as chief risk officer at Mobius Life. A lot of this, to me, is about communication. It is almost reframing why we need to look at uncertainty and why we need more information rather than jumping into detail and saying, "Let us try and quantify something. Let us try and do that." It is coming at it from a slightly different angle and thinking about, "Well, I cannot quantify that. This is why I cannot quantify it. This is the level that we have currently reached. Now, let us think about the mitigation techniques. Less about the further value, let us look about the resilience and how we stick that together."

So, I think bringing people with you and helping them understand why we are reframing it, turning it on its head, looking at it in a different way, is important. 
Mr Kaye: One thing we talked about was bringing people with you early. Picking up your point, Tim (Birse), once you have a problem and the decision-maker is trying to pass it onto somebody else to obtain the answers, it is all too late.

So, time needs to be invested with the decision-maker to help them take responsibility for the uncertainty. They cannot delegate it, but that is why bringing people with you and providing education about the issues that you are finding is important to do before it all goes wrong.

The Chair: One reason that we find it difficult to Face Up to Uncertainty is the huge pressure there is from others, especially those involved in producing financial statements and reports for certainty.

It is always expected that there will be the correct number floating out in the ether somewhere, and if we work hard enough we can catch that number in our net and bring it into land on the financial statements.

The investors have a right to know what is actually going on, but the right to know is expressed in terms of hard information rather than that nobody knows.

Mr Smerald: I think the two things that come to me are our ability to deconstruct the problem is limited. Your paper helps but I think we need more. There are very specific analytics we can do to understand the problem and its complexity, which leads to the uncertainty.

Similarly, consider the approaches we take to solving problems we do not understand very well. I have been working, myself, on a definition of what is actuarial science. I am really glad you quoted Gerd Gigerenzer, because I think his ideas on heuristics are very applicable.

So, it is that understanding of the process that we lack and my understanding of how we work is that we have a mental model of how the world works and we logically break it down into units that fit our data and we apply statistics and maths and logic to come up with some answers. Then there are some gaps and we use judgement to fill those gaps.

Now, better practice is to figure out where our methods have gaps and that is where I make this oblique comment to diversity.

We have seen the chart with the square with the big circle and the little circle. We actuaries can put a big circle in and sometimes we can put a little circle in the box, but if we talk to data scientists or management, they have other circles they can put in the box. So, we need to think more broadly about how we fill in the box working with others collaboratively, and have challenge as to how we have broken down the problem and our method.

Mr White: In practice, as we know in our area of work, there are huge uncertainties in the business. In a way, if I am a shareholder, I want the management to show that they appreciate that and are managing around it, but I do not think I am an average shareholder.

I think the way in which the stock market seems to respond, it seems to reward management who sound really confident and who declare results that go up like that every year. Of course, in a business where the truth is very uncertain and very variable, if you try and persuade yourself that you have a smooth result, eventually you end up creating uncertainty where there really was not much.

Dr H. Nazari: I am a property actuary. What I normally try to do in my work is to quantify how much uncertainty we can tolerate. So, given different assumptions, what is the margin for unpredictability?

The Chair: How does that go down? 
Dr Nazari: Generally, well. Of course they always want that responsibility to be on my shoulders to make the decision that there is enough margin, but I think it is something I can do, so I will give it back.

The Chair: Does anyone have a different approach?

Mr Smerald: Just a clarification on that approach. So, we have different degrees of uncertainty.

Doing pricing opinions, I would always grade my opinion. Is it a recommendation, meaning I have a good statistical base and the data are good? Is it a best guess where it is alright, ball park, or it is speculative? Then there is the fourth which is, this is broken, I cannot support this. That fourth one comes from wisdom, I think, more than logic. I think there is an element of intuition, but I think grading our answers is part of the solution.

The Chair: As actuaries, uncertainty is at the heart of our business. It is what differentiates us from other professionals beginning with $\mathrm{A}$, for example. I think that this toolkit has given us some very useful, explicit things to go through, and to think about, when dealing with uncertainty. I always feel it is very useful to make things explicit in this way.

How many people feel that these six principles are, in fact, the ones they have probably been using, except without necessarily thinking about them as the six things they do? How many think that new ideas have been introduced to their thinking through this paper?

Miss Strudwick: If I can add to that, are we missing any principles? We have asked ourselves that question for 3 years and we have not added to the six, but we might be biased.

Mr M. Harris: I am not sure whether you are missing one because I am not sure whether it is already included in one of the six, but one of the other things I would suggest you might want to think about is what I might call a hindsight test.

So, if I make a decision today, let us suppose in 10 years' time that has gone wrong. What I could think about today is, well, "If it has gone wrong, how might it have gone wrong? Why might it have gone wrong?"

I am not necessarily assigning a probability to how likely it is, but if it has gone wrong, will the people in 10 years' time who are looking back on it say, "I should have seen that coming"?

I think that is another useful test to do, even if I cannot decide how likely it is. If I could see it coming, I should at least have thought about it.

Mr S. McCarthy: I would be interested in your thoughts on dealing with interested parties who are a bit ignorant. So, my example would be somebody who is invested in a hedge fund and they want the manager to make all these noises when really the manager knows a lot but cannot predict the future. So, how do you deal with these ignorant parties who will pillory you if you get it wrong, even if you have done your best?

Mr Galbraith: Sticking on my other hat of the professionalism working party, where would you bring professionalism into this? What are the implications of doing a certain course of action or not doing a certain course of action or thinking about the communication or bringing people with you who maybe you should not be bringing with you? How have the authors thought about the professionalism aspects?

The Chair: I think those two points there go very nicely together. 
Mr White: In our title, we had Managing Uncertainty with Professionalism. We decided it was a bit ridiculous and presumptive to put professionalism in the title of the paper. Because we had the word professionalism in there, last year we were asked to do the professionalism slot for GIRO. We had the papers as background, we had the case study, and the way you deliver a professionalism session is partly by giving people a really difficult question and allowing an uncomfortable silence. "What would you do?"

It really was all about how do you do your professional duty and pointing out the fact that things are uncertain, etc, whilst there are so many human pressures not to do it. We used it as a case study.

The Chair: Did any good ideas come out of it?

Miss Strudwick: To add to what Martin (White) has said, I suppose a key part of the "do not be fooled" principle is that where there is less uncertainty about evaluation, then it is quite easy. You just build your model and calculate your estimate and you are done. Where there is a lot of uncertainty and the model might not be appropriate, as such, there is a lot of bias. I do think that professionalism is at the heart of the paper.

But do not be fooled that it is very important in that environment that you do try to understand where the different decision-makers and stakeholders are coming from, and whether that changes your view or not.

At the end of the day, as a professional, you do need to give your view and give the basis for your view.

Where there is a lot of uncertainty I think the climate change research is very interesting, because they can obtain direct feedback. They can look at communicating the risks of climate change to the general public, and then measure how many people do their recycling. So there is a lot of feedback.

You can see that a lay person responds better if they have more of an understanding of your mental map of the problem and if you talk of specifics, like scenarios, or numbers, and situations. I think that works well even when we are dealing with quite complex modelling.

If you can lay out the process rather than hide behind the mathematical terms, or the uncertainty and the probabilities and the distributions, and try to draw out the scenario and situations, that can help people engage with what you are doing and you can share some of the pain of having to be the expert, and make a call with the person who is using your advice. Just try to get them on board with how much uncertainty there is and some of the issues surrounding it.

Mr P. D. Needleman, F.I.A.: In listening to the discussion, I am prompted by what Melinda (Strudwick) was saying. We are meant to be the experts on uncertainty. Other than probability, which most people do not understand, I do not think we have a very good language to describe uncertainty. Certainly, using scenarios to try to illustrate it is very helpful. I do believe the accounting profession, for example, does have some sort of common language they use to describe events, depending on their degree of likelihood.

Is that something the working party might like to think about as the next step in obtaining a common language which is better than a 1-in-200 event or as a probabilistic-type language, something that the man in the street can understand and we can use as a common base to communicate amongst ourselves and with others? I think that might be quite helpful.

The Chair: Does anyone want to respond?

Mr Kaye: Well, there is a list of types of uncertainty, which was drawn partly from academia, from somebody who had a list of over 20 , I think, but we have it down to 7 . In the section in the paper 
on deconstructing the problem, there is a list which you can use as a, "Hey, look we have some uncertainty here which is all to do with quantitative uncertainty. We have some other uncertainty due to complete ignorance or whatever, and social issues." Continuing that discussion and improving it, and using that language would be a good thing.

Miss Strudwick: Early on, Paul (Kaye) did make an excellent suggestion, which was why do not we have a traffic light rating for uncertainty similar to food packaging. The average shopper understands that a red item is a risky item to put in their shopping basket. Paul did suggest that, and we played around with it for a while, but then we decided that it trivialised the situation. It is hard to come up with the same simple grouping that works in all situations. Well, certainly, it is something we can think about again. It is not easy to do.

Mr White: I think there have been a number of GIRO working parties that have talked about communicating uncertainty. In a way, we evolved through, "What can we do to alert people about the problem?," or the 1-in-200 and the false confidence, to communicating our issues with clients. We moved to trying to help people make sensible decisions. That has been our journey.

One of the points I wanted to make is in response to the hindsight point. If you make a judgement and you look back in 10 years, you think, "Oh dear." It is worth considering in terms of improving judgement. When you make your judgement, try to write down why you made that at the time, and look back at your notes. You may find that really revealing. It is quite a nasty discipline but worth trying.

Mr Marcuson: I wanted to make three points:

First, the challenge that you are often faced with when trying to deconstruct the problem is you are trying to take a decision in a field of uncertainty. The process of making a decision is something that is emotionally loaded and very often the challenge is the interaction between advisor and recipient or adviser and decision-maker which introduces emotional aspects in many contexts.

You can map out a different, but similar problem to try to work out what are the assumptions that you could agree on, and what is the model that you could agree on and disagree on in the face of this uncertainty. Then as a separate stage in the process, trying to think about what is the decision given that conclusion? You can legitimately have different professional views on what the right assumption might be, but it could be particularly difficult to have differences of views on what is the right decision if you do not set to one side the emotional aspects of the decision and just try to get back to the facts.

The second point I wanted to make was in regard to how we think about the role of margins in our estimates. One of the challenges that Solvency II has put upon us is the idea of coming up with the best estimate. There is a real difficulty with a margin because the traditional actuarial approach might have been, where there was a bit of uncertainty, to include a margin in the numbers.

This is particularly in the sort of environment where you are providing advice, and knowing if you are the actuary discussing with the underwriter their profits for the year, then if you start with a bit of a margin in the number, then you know you are going to be beaten down.

You can then try to come to an accommodation at a point where you know you can accept the numbers. There really is a difficult challenge here. What is the right strategy to deploy if you know that there is going to be a bit of a "dance" to be done?

I would be really interested in people's experiences of how they go about that, because one thing you know if you give advice on a whole set of results is that people do cherry-pick and they do try to whittle you down. With that knowledge in advance, you therefore try to get your defences in first. 
The third point I want to make was coming back to the point about shareholder value and shareholder value maximisation. In a sense, you are viewing the exercise as how do you maximise shareholder value subject to being able to survive certain risks?

It is interesting to reflect tonight upon what would have happened had the conversation 30 years ago not gone in the direction it did, but rather along the lines of "how do we maximise the probability of the companies surviving for 5 or 10 years, subject to achieving a certain shareholder value?" Now, I do not know which of these is right or wrong or better but it is perhaps interesting to reflect that it is not obvious that one of those may be better than the other. It just happens to be the way that society has chosen to go.

Mr Birse: I think what is really helpful is the peer review process and I would like to suggest having two levels of peer review. I have found it helpful myself.

I am not suggesting even more work, but where there is complex modelling, you have somebody who understands how to do the sums who can peer-review that piece of work. You also have someone, perhaps a bit longer in the tooth, like me, who might not be able to understand how to do the sums at all anymore, but can come to the problem with an overview, with a wealth of experience and produce the gut-feel peer review to complement the "do the numbers look right"?

The Chair: Thank you. Also, of course, this is somewhere where the professional support service can sometimes help, at least not on the details but in suggesting ways that you can handle the issue in a constructive way.

Mr N. C. De Silva, F.I.A.: I thought this paper was really good and particularly those six fundamental principles. I think we tend to focus a lot on the modelling and the uncertainty side of things and the explanation of those aspects. I think adaptability and resilience are very important things that we tend, perhaps, to focus on a little bit less.

Perhaps the most important aspect, I think, is bringing people with you. We were talking earlier about some ignorant people on the receiving side, perhaps. I think that issue is really important. Melinda (Strudwick) gave a few examples of good ways of dealing with that, but I think, certainly, that bringing people with you is important.

The other thing is an observation. As a user of some of this information, as actuaries we tend to be the expert. If you tend to be the expert, particularly in the example of purchase consideration, what would your opinion be? I think we tend to stand back and say well there is too much uncertainty. I am not the decision-maker. We tend not to give our own opinions particularly in the case of merger and acquisition decisions. I think an opinion is quite useful, from the receiver's point of view.

Mr P. Chaaya, F.I.A.: I wanted to come back to Melinda (Strudwick)'s point because it really resonated with me, around mental maps. Sometimes we actuaries can become wrapped up in the idea of the purpose of the model being to reach an answer or to obtain the right answer.

Whereas, I think a lot of the time the real value in the model is providing a structured framework for thinking about the problem. Providing a structured framework can lead to transparency if we communicate it well and can lead us to facilitate collection of thoughts, ideas, assumptions, and to have them together in one place so that they are then visible. I think that is often of considerable value.

Even if the outcome is a very wide range and we cannot give a specific answer and we say, the answer is somewhere within that range. The fact that we are able to articulate what the assumptions are that have led us to that point and can be very useful to other stakeholders.

I would like to add that there is part of the aspect of bringing people with you, I think that is very much part of that proposal. If people feel that they are dealing with a black box, perhaps they demand 
an answer. If they feel that they can communicate with and engage with a set of assumptions that are being put together in a logical way that they can understand, I think that can be very useful.

Mr White: On that point, the question of bringing people with you, if you know you have to give bad news, and leaving it until the last minute is quite often the scenario that is painted in those very uncomfortable videos we have to look at for professional training. If you know that there is a difficult decision, a difficult thing to be faced up to, if you can identify your relevant counterparts in the business and get them to buy in a bit to the fact, "But there is a little problem here and there is a problem there. Oh, there is a problem there," then when you present it, it is not such a thing coming from you. They slightly own it already. So, you have to take time to get people to digest bad news and if you try to do it in a lump you are going to receive a nasty emotional reaction.

The Chair: Keep the channels open and keep talking.

Mr White: Be seen to listen and if you say, much of this comes from you guys, not just me, it is going to be a lot more powerful

Miss Strudwick: I do not know if Henry Johnson will mind me mentioning, but he was part of the group. At the point we were discussing case studies, and he was talking about liability reserving and managing what could be perceived by a reserve committee to be a blip or could it be a trend in your incurred claims.

If you leave the conversation about the risk and liability reserves, and how they could deteriorate over the longer term until the point you have the blip, it is very hard to get the reserving committee, or the board, to react and perhaps introduce additional prudence into the reserves. Whereas, if you have already laid the trail and you have talked about the potential risks and vulnerabilities in the reserves before the blip arises, you are going to be in a much better position to persuade that committee that this is a circumstance where we might need additional prudence. This could be a trend and we need to monitor that.

It is to Martin (White)'s point of starting early, but perhaps even before the uncertain situation starts crystallising.

The Chair: Of course, we have that on a far larger scale, with the mortality improvements that we were seeing 20, 15 years ago and we did not know whether it was a blip or a trend.

Mr Smerald: You were asking about what you might have missed. In a way, you missed nothing but also, I think you missed something really obvious. You are describing how to live within a process but you have not actually described a process.

I am thinking of your first example. You talked about a capped model of 1-in-200 event and what if you have a 1-in-1,000 event. "Oh dear, you know, what do I do?" Well, you should expect that that could happen so you should prearrange with management, perhaps, what you would do. How you would monitor your underlying assumptions all the way along, that you might have seen something coming that, "Well, if we have this type of event, something's going to happen if so, we can Winsorize, meaning we will cap it at a 1 -in-200 and we will put it into the model and get some impact right away."

That is what we will do and then we will do more work and will spend money and improve the model. I think just having a process where you have decided on how you are going to monitor things, how you are going to react when something goes wrong, feels like something that should be there.

Mr White: I think what you are describing is getting management systematically to face up to the existence of the uncertainty at the outset. 
Mr Smerald: It is in there, yes.

Miss Strudwick: Robyn Wilkinson, another venerable member of our group, brought us the Boston Marathon example, which is after $9 / 11$. There were many people in one place and they knew there was a lot of risk to life but they did not know how or where that risk was coming from. How that could happen? 9/11 had just changed people's views of what catastrophe could be.

There was a lot of event planning and the authorities took the decision just to improve communications and coordination between the hospitals and the police and the army so that if something happened the communication channels would be there and decisions could be made quickly.

When, I think, a bomb went off and a number of people were hurt and Emergency Services could not access them, they had a plan that clicked in to action. They cleared beds in hospitals and very few lives were lost.

Whilst I do accept the fact that you can persuade an organisation to think about where the risks are and what could happen and prepare for that, there is also a piece which is you do not always know what is going to bite you or where it will come from.

A good starting point is to think about outcomes and what would hurt the most and what can you do to protect against the outcome. Even if you do not know how it might arise.

The Chair: Of course, this is where scenarios are so useful because if you do not focus on the detail of the scenario but focus on the outcomes, then that really helps to concentrate the mind.

Miss Strudwick: It does, yes.

Mr Harris: It just struck me, as you were talking about the Boston Marathon, that this is exactly the kind of thing I had in mind for that hindsight test. You cannot assign a probability to this thing that is going to happen, but it is a bad outcome and you know it is possible.

What steps might you take to mitigate that risk and what does it mean? Again, picking up on your point, Martin (White), what does it mean for the notes that you should record at the time that you made the decision?

That is the judgement. That is how you are going to defend yourself against that judgement. If it is something that you could not possibly have foreseen, no one is going to blame you, but if you could see that something could happen then you are going to be judged in that light.

Miss Strudwick: Thank you.

Mr Simmons: The story that Melinda (Strudwick) mentioned is all about adaptability. I know it was mentioned by a speaker before, but I just wanted to emphasise it again because I really think it is important.

The key is that uncertainty is there, so how do we adapt to it, and that is where we need to focus. Not on how we can quantify and model it, since we do not know what is going to happen, but how do we adapt if it does?

Dr J. T. H. Lo, F.I.A. (closing the discussion): I think it was Alex (Marcuson) who raised the point, and maybe some of the others in the audience as well, about maximising shareholder value. I always find it quite interesting. Are we maximising shareholder value now or are we trying to reach a certain return, but minimising risk?

The idea is that we are trying to reach some kind of return on capital, and that return on capital is usually on a basis of the best estimate on the long-term average. The long-term average means 
that the company needs to be around for long enough for that average to be realised. We need to think a little bit more about that type of thinking.

The second point is about complexity and diversity. One immediate thought that I had was on how do we bring diversity back together? Many people say that diversity and inclusion is very challenging. The one thing that inspired me was about judgement with hindsight. Somebody else mentioned this, and that suggested to me that, at the very least, when I go back to my office I will try to take steps not to have some blame culture in my office. Proper challenge, yes, but blame culture may not be, as such, a good idea.

Finally, the common language question I found quite fascinating. The 1-in-200, 1-in-100 kind of language is very difficult because we are plagued by not knowing the level of granularity.

For example, if in my company there are 70 classes of business, then over the period of 10 years I should really experience three or four 1-in-200 events. So, from that perspective, it is not really that helpful when we say, 1-in-200 or 1-in-1,000 or something like that. When we go granular enough, there will be some 1-in-200 events around.

I do think that Solvency II has lots of shortcomings, but one of the tasks that Solvency II has done very well is defined the context of what that 1-in-200 is. It is a 1-year horizon, movement or Solvency II balance sheet, etc. You know exactly how you are supposed to interpret it even though it is very difficult to measure.

In terms of common language, maybe some kind ranking could be interesting. Maybe ranking against scenarios or against case studies. Which common case study or scenarios do you think this, or that, particular problem that you are doing, might be more or less uncertain? Maybe something like that against a few dimensions, but I suppose these scenarios and case studies need to be quite neutral. Otherwise, you might bias the decision you are trying to make from those types of uncertainty.

Finally, I have further reading that I might suggest to you. There are quite a number of books around about uncertainty, and these books and papers I found particularly interesting. Maybe you would as well.

If I could begin with the 1995 paper by the researcher Peter Smith, the title of which was on The Unintended Consequences of Publishing Performance Data in the Public Sector. This goes to the point about how, sometimes, it is just difficult to quantify all the things that we want to quantify. This paper highlights eight pitfalls and, usefully, it has some remedies against those pitfalls. It is an old paper but it could be a good reference for the actuarial profession where many of us are engaging in producing matrix and quantification of various sorts.

The next book is the 2008 book called Uncertainty and Risk, Multidisciplinary Perspectives. It was edited by Gabriele Bammer and Michael Smithson, and it grew out of an academic symposium in Australia. There is a collection of essays from a very wide spectrum of disciplines from the humanities and creative industry, the policing, social and health services, disaster management, terrorism intelligence gathering, science and religion. We are not alone in trying to grapple with uncertainty, and it was fascinating read, to see how even historians can think about how to deal with uncertainty. Interestingly, it had little space on the financial sector but it does include an essay and communication and engagement with regard to policies and actions against climate change impact by the researcher Nick Pidgeon.

A third book was published 8 years ago and is called The Known, The Unknown, and the Unknowable and Financial Risk Management. It was edited by Francis Diebold, Neil Doherty and Richard Herring. This is also a collection of essays on managing uncertainty, in the financial sector this time. Of course, it includes insurance and financial markets but it also considers property and more niche investments. What I rather liked about this book is that it grapples with the upside potentials more deeply. There are several essays where they have taught you a strategy to, basically, make money, when there is deep uncertainty. If we were to gain professional trust in our areas, the ability to help make decisions that catch hold of upside uncertainty is a relatively important one. 
I love a story book and this is a relatively depressing story book. It is called Man-made Catastrophes and Risk Information Concealment. It has about 20 or so case studies, painstakingly put together by a couple of Zurich ETH researchers. What they have done is they have looked at nuclear disasters. They have looked at financial crises, vast industrial pollution events and other corporate scandals and all.

While they are trying to draw common themes from them, and one of them is risk concealment, how information from the technician, from the people who are doing day-to-day work, is failing to go up to the decision-makers. There is also an analysis of incentives and organisation culture. In addition, it also discusses failings in disaster management and containment. It is painstaking to put together these case studies and, of course, the working party authors would know that as well.

I feel we could do more of this. It provides hopeful lessons for the future. Also, it helps towards a common language for the further collaboration. This book advocates wider risk information sharing. I sometimes wonder how our profession could play a part in this.

Mr White: On behalf of the authors, I would like to thank everyone for their contributions and we would be very pleased to receive any written or emailed contributions after the event. It has taken us many years, albeit very enjoyable years, to get to this point. We would not mind waiting a little more for some more contributions and we also need to do a bit of work on the paper to get it into a format that suitable for publication in BAJ. Things such as bringing all the references in one place, and, I think, now adding all the references that Joe (Lo) has given to us just now.

Our whole purpose in writing the paper was it should be of practical use and I think that I found the discussion of this quite encouraging in that regard. I particularly liked Joe (Lo)'s mention of blame culture. If you are going to make good decisions in the face of uncertainty, there has to be a clear recognition of a distinction between a sensible decision that turns out lucky, and a badly judged decision that turns out lucky. You should be rewarded for the first and definitely not for the second. Is this what happens in practice? A blame culture could lead you to be risk-adverse and not to make decisions that you really should make. It would be good if there was a way of jointly sharing responsibility for difficult decisions so that the team as a whole is armoured against excessive risk aversion.

Finally, I would like to leave you with a couple of suggestions for yet more reading. We tried to take out some of the fear about managing uncertainty by discussing some ideas for dealing with it. If you have enjoyed the paper, there is one of the references that I cannot recommend too strongly, which is Good Strategy, Bad Strategy by Richard Rumelt, which is mentioned on Page 30 of our draft paper. I think you will find it empowering and encouraging. I certainly did.

John Kay and Mervyn King are currently working on a book on the subject of Radical Uncertainty, which I believe is expected out sometime this year.

Cite this article: Managing uncertainty - principles for improved decision-making. British Actuarial Journal. https://doi.org/ $10.1017 /$ S1357321719000205 